\title{
Socio-Economic Determinants of Investment among low income Households in South Africa
}

\author{
${ }^{1}$ Abiola B. A. , ${ }^{2}$ Obokoh L.O. PhD, FCA \\ ${ }^{1}$ School of Economics, Faculty of Commerce, University of Cape Town, Cape Town, 8000, \\ Cape Town, South Africa \\ ${ }^{2}$ Cost and Management Accounting Department, Faculty of Business \& Management \\ Sciences, Cape Peninsula University of Technology, Po Box 652, Cape Town, 8000, Cape \\ Town, South Africa
}

\begin{abstract}
The ownership of the means of production and the history of apartheid in South Africa are always linked to the level of inequality in the country. South Africa has been described as one of the world's most unequal society not only because of the figure of Gini-coefficient of (0.6) but also because of the racial pattern of wealth and income distribution. As a result, this research examines the socio-economic determinants of investment among low income households also referred to as Non-Ricardian Households (NRH) in South Africa. The Ricardian Households (RH) comprise medium and high-income households, who are involved in the financial market, participate in buying of bonds or stocks, and are classified as saving households. Non-Ricardian households comprise of low-income households, which largely dependent on government welfare grants for sustenance, and are classified as the low investment households. The research uses the National Income Dynamics Study (NIDS) dataset (wave one to five). Socio-economic characteristics of NRH in South Africa are determined by using panel estimators including Pooled OLS, fixed and random effects methods. The result show household income, household size, household geographical location and household grants, among others, are major determinants of households' investment in South Africa. Government grants to households is found to impact negatively on households' investment. The grants received by more than 17 million households' costs the government over R170 billion in 2019 reveals households over-depend on the government for present and future expenditures and discourage productive efficiency.
\end{abstract}

Key words: Investment, Non-Ricardian Households, government grant. 